\title{
Research on Firm IT Capability and Competitive Advantages
}

\author{
Jingfu Guo, Lin Sun, Lijuan Zhong \\ Dalian University for Nationalities, Dalian 116600, China \\ E-mail: guojingfu@sina.com
}

\begin{abstract}
Effective and efficient use of IT capability is a key factor for a firm to get competitive advantages. This paper develops the concept of IT-capability and it's function mechanism, firm IT resources are classified as IT infrastructure, human IT resources, and IT relationship infrastructure as well as IT-Related capabilities. The paper discusses valuable, competitive, and dynamic capabilities as three related IT capabilities, and presents a model that describes relationship between these capabilities and competitive advantages. This study also interprets that a firm's ability to effectively leverage its IT investments by developing a strong IT capability can result in improving firms performances, such as integration of customer relationship management (CRM), E-Supply chain management etc.
\end{abstract}

Keywords: IT capability, Competitive advantage, Firm performance, IT infrastructure

\section{Introduction}

IT competence of a corporation is an important factor of a company's abilities, and it also attracts many researchers interests in the relative academic fields. On this concept, different scholars have different opinions and viewpoints, and there isn't an uniform definition until now. Ross (Jeanne W. Ross etc. 1996) first brought up the concept of IT capability, he defined IT capability as the ability that a company's controlling its IT expenditure and cost, and delivering in time to promote the realization of the company's targets. Ross believed that the IT capability comes from three kinds of relative resources, they are the IT human resources, IT technology resources and the IT relationship resources. Bharadwaj (S. Anandhi A.Bharadwaj, 2000) also did research about the issues, he defined this ability as the competence to mobilize and deploy its IT-based resources and this kind of IT resource should be combined with other resources of the company. While Van der heijden thought that IT capabilities are of organizing abilities based on a firm's behaviors, business processing, technology and resources. Chinese scholar Zeng qingfeng (Zeng \& Huang, 2003) defined IT capability as a competence that a company mobilizes its related IT resources to achieve operation goals. We can find that IT resources are important to a company and its IT capability. Augmenting the conceptual analysis of IT's effects on firm performance is the resource-based view (RBV) of the firm which links the performance of organizations to resources and skills that are firm-specific, rare, and difficult to imitate or substitute. The resource-based view is presently the dominant theoretical perspective in strategic management literature, and focuses on costly-to-copy attributes of a firm which are seen as the fundamental drivers of performance.

Now there have been a lot of researches about IT capabilities, they were carried out from different viewpoints, but these studies seldom studied the relations between IT capabilities and competitive advantages as well as the mechanism how IT capabilities can lead to competitive advantages. In the following paragraphs, the identification of IT as an organizational capability created by the interaction of IT infrastructure, human IT resources, and IT-related capabilities are explicated, it is also to study and interpret the mechanism between IT capability and competitive advantages by an examination of the links between IT resources and firm performances.

\section{IT related abilities and function mechanism}

Firms that achieve competitive advantage through IT have also learned to combine effectively their IT resources to create an overall IT capability, successful firms employ their technology base and human IT skills to develop IT-enabled intangibles such as customer orientation, synergy, and superior organizational knowledge.

\subsection{Human IT resources}

The corporation human resources generally comprise training experience, relationships, and insights of employees. The critical dimensions of human IT resources include: (1) technical IT skills, such as programming, systems analysis and design, and competencies in emerging technologies, and (2) the managerial IT skills, which include abilities such as the effective management of IS functions, coordination and interaction with user community, and project management and leadership skills. (D. G. Copeland and J. L. McKenney, 1988). Technical and managerial IT skills typically evolve over long periods of time through the accumulation of experience. Furthermore, managerial IT skills are often tacit, dependent on other interpersonal relationships, which may take years to develop. For example, creating a user community that welcomes technological change and embraces new systems takes several years over which the IS group has to engage in mutual trust building and commitment to share goals. 


\subsection{Leader's IT capabilities and applications}

Recently, some researchers have framed the discussion in terms of IT capabilities, and argue that managing IT is a capability that can create uniqueness and provide organizations a competitive advantage. Thus, despite uniformly high investments in technology, such organizational capabilities tend to be heterogeneously distributed across firms leading to differential business value to firms by improving organizational efficiency and effectiveness.

\subsection{IT infrastructure}

A firm's overall IT infrastructure comprises the computer and communication technologies and the shareable technical platforms and databases. The IT infrastructure is a shared information delivery base, the business functionality of which has been defined in terms of its reach and range. While the reach determines the locations that the platform can access and to which it can link, its range defines the kind of information that can be seamlessly and automatically shared across systems and services. A firm's IT infrastructure has been described as a major business resource and a key source for attaining long-term competitive advantage. A firm's IT infrastructure which is in good conditions and has flexible properties can meet the requirements of new IT application projects. The IT infrastructure provides the resources that make feasible innovation and continuous improvement of products. The unique characteristics of the IT infrastructure that enable firms to implement the right applications at the right time render the cost and value of technological innovation different from different firms.

\subsection{IT relationship infrastructure}

The IT relationship infrastructure consists of sharing risk and responsibility of IT application between IT and business unit management. Only business units are in a position to effectively utilize IT in their strategy and daily work. Therefore, in order to make effective use of IT, the IT responsibilities and roles should be shared between line management and IT management. Unless line management and IT groups call coordinate their responsibilities and accountabilities, the firm is unlikely to acquire, deploy, and leverage its IT resources effectively. One major component of the relationship infrastructure is the trust that is developed between IT groups and business units. Because development of trust takes time, thus, according to Barney and Hansen (J. B. Barney, and M. Hansen, 1994), the relationship infrastructure constitutes a source of competitive advantage for the firm. We posit that once an organization succeeds in forming trust between IT groups and business units, their interaction enables knowledge flow and knowledge diffusion throughout the organization, which is likely to bring a greater appreciation for each unit's work, expertise, and roles in the organization.

\subsection{IT-Related capabilities}

In fact, several key organizational intangible factors, such as value capabilities, competitive capabilities and dynamic capabilities have been recognized as key drivers of superior firm performance. We argue that such capabilities are not only valuable but heterogeneously distributed and difficult to transfer. (F. J. Mata et al, 2001) provide two reasons why such managerial IT capabilities are likely to be the major source of competitive advantage. First, they evolve through history and "learning by doing" making these experiences very heterogeneous across firms. Second, the relationship between IT managers and those in other business functions develop over years, which are socially complex, and involve a number of minor decisions over time. Superior IT capabilities described above allow firms to respond quickly to environmental threats and leverage opportunities, this broader organizational capability captures the ability to search, explore, acquire, assimilate, and applies knowledge about resources, opportunities, and how resources can be configured to exploit opportunities.

Based on above research, here we propose the mechanism model(Fig.1), it shows IT capability affects business productivity by IT application programs, and how IT capability brings competitive advantages.

\section{IT capability and firm competitive advantages}

Competitive advantage is rooted in the deployment and use of idiosyncratic valuable, and inimitable resources and capabilities. Firms leverage two distinct strategic mechanisms: resource-picking and capability-building. Firms that have superior knowledge capabilities do better on acquiring resources and building capabilities. Capability-building refers to the ability of firms to build unique competencies and capabilities that call leverage their resources, these capabilities are embedded, making them comparatively more valuable and inimitable, and therefore superior to resources as determinants of long-term performances.

\subsection{Synergy}

Synergy refers to the sharing of resources and capabilities across organizational divisions. Beyond operational efficiencies, knowledge and information sharing across functional units enables firms to be more flexible and to respond faster to market needs. As Brown and Duguid (J. S. Brown and P. Duguid, 1991) point out, information technologies geared toward creating organizational synergies can aid in the delivery of needed resources by 
removing the physical, spatial, and temporal limitations to communication. As a result, problems that once took two weeks to solve are now solved overnight. Technologies such as CAD/CAM permit inter-organizational design teams to share engineering drawings and foster greater cooperation in buyer-supplier relationships.

\subsection{Integration of customer relationship management (CRM)}

The development of IT capability speeds up the integration process of world economy, the applications of Internet, Intranet and E-commerce change completely the situation that enterprise faces. In order to keep a position in dynamic and changeable market, the enterprises of all nations are trying to seek various efficient ways to strengthen their own core competition. Many enterprises apply BPR to redesign the core business process, optimize resources disposition by applying EPR and manage all links of the whole supply chain by using system method in the form of supply chain. To the departments of sales, marketing service and technological support in an enterprise, CRM makes it true to share the information and automation for different business departments. CRM can improve and mediate the previous business process, reach the needs of customers and cut down the operation cost in the all operation flows.

\subsection{E-Supply chain management}

The prevalence of E-Commerce has profound effects on enterprise supply chain, traditional supply chain was based on linear value chain. Based on the knowledge of the value chain changes, it is appropriate to define the supply chain in network economy as a production network formed of successive supplier-customer links and proceeding through value creation activities of any member to ensure that either product or service reaches the end customer. Electronic supply chain is a large, dynamic integrated network of complex but well-defined relationships with multiple channels in the business, which deliver accurate and effective information to everyone in the network. With advanced IT capabilities, electronic supply chain management (E-SCM) has apparent distinguishable features:

1) Whole value chain network connection

2) Virtual integration of collaborative value creation

3) Dynamic integration of business processes and intelligence

4) Multi-levels and extensive integration of information flows

\subsection{Global market opportunities}

The goal of enterprises is to effectively realize resources integration across space and time, therefore, openness, expansiveness, compatibility, intelligentialization and safety are the goals that enterprises integration management systems are to achieve. Internet based information technology and its further development will have great effect on the evolution of manufacture and organization management mode. Market opportunities and management decisions base on information. Current Internet technology does pretty well on global information sharing and it has become a part of our society. Large numbers of researches are proving that Advanced IT capabilities will promote cross-space and cross-department communication and coalition in order to integrate knowledge resources of corporations in a more significant way, which is not only feasible but also necessary. With the help of Internet, Businesses easily build up the information platform with much more partners, so corporations can easy get more market opportunities.

\section{Conclusion}

Superior IT capability leads to improved firm performances, whether IT capability can improve firm's competitive advantage depends on IT capability promotes firms innovation on application of IT. Organization design elements serve to create an environment in which IT human beings can leverage not only their own technical and managerial skills but can also effectively bring to bear the assets of the entire socio-technical network to which the member belongs. We argue that although the quality of IT infrastructure may not be a direct source of differentiation, the ability to effectively leverage that infrastructure is. Companies that have IT personnel, who are knowledgeable about business strategy, competition, and business opportunities, create a unique competence that can lead to better leveraging of IT infrastructure, thereby leading to competitive advantages.

\section{References}

Jeanne W. Ross etc. (1996). Develop long-term competitiveness through IT assets. Sloan management review, fall.

S. Anandhi A.Bharadwaj. (2000). Resourced-based perspective on information technology capability and firm performance: An empirical investigation. MIS Quarterly, vol,24.

Zeng, Qingfeng \& Huang, Lihua. (2003). Research on firm performance effected from IT capabilities (in Chinese). Management information system, 28-35, No.5.

D. G. Copeland and J. L. McKenney. (1988). Airline Reservation system: Lessons from history. MIS quarterly, 
353-370, (12:3).

J. B. Barney, and M. Hansen. (1994).Trustworthiness as a source of competitive advantage. Strategic management journal, 175-190, (15).

F. J. Mata et al. (2001). Information technology and sustained competitive advantages: A resource based analysis. MIS Quarterly, 478-505, (22).

J. S. Brown and P. Duguid, (1991). Organizational learning and communities of practice toward a unified view of working, learning and innovation. Organization Science, 40-57, (2).

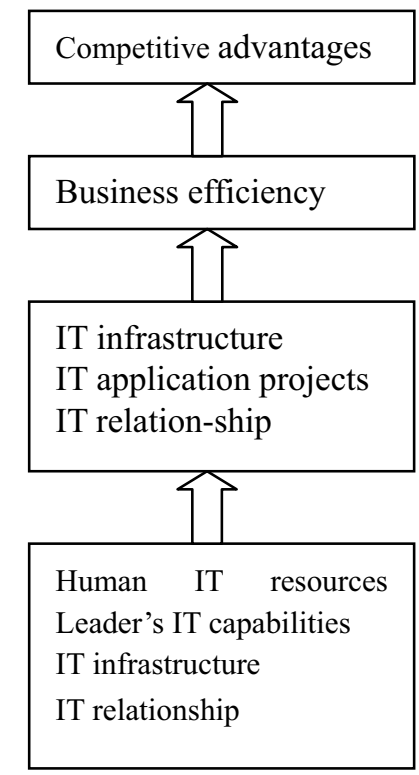

Figure 1. Mechanism of IT capability 